\title{
Perkütan Nefrolitotomide Renal Dilatasyon Yöntemlerinin Sonuç ve Komplikasyonlar Üzerine Etkisi
}

\section{Efficacy of Renal Dilatation Methods on Results and Complications in Percutaneous Nephrolithotomy}

\author{
Arif KOL, Erhan ATEŞ, Tümay İPEKÇİ \\ ${ }^{1}$ Aydın Adnan Menderes Üniversitesi Tıp Fakültesi, Üroloji Anabilim Dalı, Aydın, Türkiye \\ 2 Başkent Üniversitesi Tıp Fakültesi Alanya Araştırma ve Uygulama Merkezi, Üroloji Anabilim Dalı, Antalya, Türkiye
}

Yazışma Adresi

Correspondence Address

\section{Arif KOL \\ Aydın Adnan Menderes \\ Üniversitesi Tıp Fakültesi, Üroloji \\ Anabilim Dalı, Aydın, Türkiye}

drarifkol@gmail.com

Geliş tarihi / Received : Kas 05, 2020 Kabul tarihi / Accepted : Ara 04, 2020 Elektronik yayın tarihi : Eyl 01, 2021 Online published

Cite this article as:

Bu makalede yapılacak atıf:

Kol A, Ateș E, İpekçi T

Perkütan Nefrolitotomide Renal Dilatasyon Yöntemlerinin Sonuç

ve Komplikasyonlar Üzerine Etkisi

Akd Tıp D / 2021; 7(3):355-361

Arif KOL

ORCID ID: 0000-0002-3682-3661 Erhan ATEŞ

ORCID ID: 0000-0002-9677-5673

Tümay İPEKÇI

ORCID ID: 0000-0002-2755-0526

\section{ÖZ}

Amaç:

Perkütan nefrolitotomide kullanılan iki farklı renal dilatasyon yönteminin taşsızlık oranları ve komplikasyonlar üzerine olan etkilerini karşılaştırmayı amaçladık.

\section{Yöntem:}

Haziran 2013-Aralık 2018 tarihleri arasında iki ayrı merkezde, renal pelvis ve kaliks taşları nedeni ile perkütan nefrolitotomi uygulanan hastaların verileri retrospektif olarak değerlendirildi. Tüm hastaların, komorbid hastalıkları, geçirilmiş taş cerrahisi öyküleri, yaş gibi demografik özelliklerinin yanı sıra taş tarafı, taş sayısı ve taş yükü, Hounsfield Unit değeri ve hidronefroz derecesi kaydedildi. Hastalar, kullanılan dilatasyon yöntemine göre balon dilatasyon (Grup 1), amplatz seri dilatasyon (Grup 2) ve kombine (Grup 3) olmak üzere 3 gruba ayrıldı. Operasyon süreleri, postoperatif hemoglobin düşüşü, transfüzyon gereksinimi, taşsızlık oranı, hastanede kalış ve nefrostomi alınma süreleri ile komplikasyon oranları gruplar arasında karşılaştıııldı.

\section{Bulgular:}

Gruplar arasında ortalama operasyon süreleri $(\mathrm{p}=0,185)$, taşsızlık oranları $(\mathrm{p}=0,313)$ ve komplikasyonlar $(\mathrm{p}=0,053)$ açısından istatistiki anlamlı fark izlenmedi. Postoperatif hemoglobin ve hematokrit düşüşü en fazla grup 3 hastalarda gözlendi. Grup 1 ve grup 2 hastalar arasında ise anlamlı fark yoktu ( $\mathrm{p}=0,373)$. Benzer şekilde grup 1 hastalarda, grup 2'ye göre daha fazla transfüzyon ihtiyacı saptansa da anlamlı fark izlenmedi $(\mathrm{p}=0,787)$. Hastanede kalış ve nefrostomi alınma süresi ise grup 1'de anlamlı derecede daha kısa saptandı $(\mathrm{p}<0,05)$.

\section{Sonuç:}

Amplatz seri dilatatörler, komplikasyon ve taşsızlık oranları bakımından balon dilatatörlere benzer sonuçlar sunmaktadır.

Anahtar Kelimeler: Perkütan nefrolitotomi, Balon dilatatör, Amplatz Seri Dilatatör, Perkütan renal giriş, Komplikasyon.

\section{ABSTRACT:}

\section{Objective:}

We aimed to compare the effects of two different renal dilatation methods used in percutaneous nephrolithotomy on stone-free rates and complications.

Methods: In two centers between June 2013 and December 2018, the data of patients who under- 
went percutaneous nephrolithotomy for renal pelvis and calyceal stones were retrospectively evaluated. Stone side, stone number and stone burden, Hounsfield Unit value and degree of hydronephrosis were recorded as well as demographic characteristics of all patients such as comorbid diseases, history of previous stone surgery, age. The patients were divided into 3 groups according to the dilatation method used: balloon dilatation (Group 1), amplatz serial dilatation (Group 2) and combined (Group 3). Operation times, postoperative hemoglobin decrease, transfusion requirement, stone-free rate, hospital stay, time of nephrostomy and complication rates were compared between the groups.

\section{Results:}

There was no difference between the groups in terms of mean operation times $(p=0,185)$, stone-free rates $(p=0,313)$ and complications $(p=0,053)$. Postoperative hemoglobin and hematocrit decrease was mostly observed in group 3 patients. There was no significant difference between group 1 and group 2 patients $(p=0.373)$. Similarly, although the transfusion requirement was higher in group 1 patients compared to group 2, no significant difference was observed $(\mathrm{p}=0,787)$. The duration of hospital stay and nephrostomy removal time were significantly shorter in group $1(\mathrm{p}<0,005)$.

\section{Conclusion:}

Amplatz series dilators offer similar results to balloon dilators in terms of complication and stone-free rates.

Key Words: Percutaneous nephrolithotomy, Balloon dilator, Amplatz serial dilator, Percutaneous renal Access, Complication.

\section{Giriş:}

Nefrolitiyazis, dünya çapında prevalansı ortalama $\% 3,5$ düzeyinde olan üriner sistemin oldukça yaygın hastalıklarından biridir $(1,2)$. Hastaların \%25'i tedavi sonrası 5 yıl içerisinde, \%75'i ise 5-10 yılda tekrar taş nedeni ile sağlık kuruluşlarına başvurmaktadır $(1,3)$. Bu bakımdan hem hayat kalitesini bozması hem de olumsuz sosyoekonomik yönleriyle ciddi bir sağlık problemi olarak önemini korumaktadır $(1,4)$. Perkütan renal girişimlerin gerçekleştirilmesini takiben ilk kez 1976 y1lında Fernström ve Johansson, perkütan yolla renal taş cerrahisini tanımlamışlardır (5). Takip eden yıllarda perkütan nefrolitotomi (PNL), giderek açık cerrahilerin yerini almıştır. Güncel kılavuzlarda, 2 santimetreden büyük böbrek taşlarında PNL önerilmektedir (6). PNL'de, taş boyutu, taş lokalizasyonu, renal obstrüksiyon olup olmaması gibi taşa bağlı faktörlerin yanı sıra, obezite, renal anomali varlığı, komorbidite ve antikoagülan tedavi gibi hastaya bağlı birçok etken de başarı ve komplikasyonlar üzerine etki etmektedir (6, 7). Bunun yanında kullanılan yöntemde önemli bir faktördür. Cerrahinin ilk aşaması, toplayıcı sisteme ulaşmayı sağlayacak etkin ve güvenli bir perkütan yol oluşturulmasıdır. Bu aşamanın önemli bir parçası da giriş hattının dilatasyonudur. $\mathrm{Bu}$ amaçla, balon dilatatörler, metal teloskopik dilatatörler ve amplatz semirijit dilatatörler kullanılmaktadır (8). Dilatasyon yönteminin seçiminde, cerrahın tecrübesi yanında, maliyet, hastaya ilişkin faktörler ve olası komplikasyon riskleri etken olmaktadır. Maliyet problemi özellikle gelişmekte olan ülkelerde seri dilatasyon yöntemlerinin kullanımını ön plana çıkarmaktadır (9).

$\mathrm{Bu}$ çalışmada PNL yapılan hastalarda, amplatz, balon ve kombine dilatasyon yöntemlerinin taşsızlık oranı ve komplikasyonlar üzerine etkisinin değerlendirilmesi amaçlandı.

\section{Gereç ve Yöntem:}

Araştırmada iki ayrı 3.basamak üniversite hastanesinin veri tabanları kullanıldı. Haziran 2013-Aralık 2018 tarihleri arasında, renal pelvis ve kaliks taşları nedeni ile perkütan nefrolitotomi operasyonu uygulanılan hastaların verileri retrospektif olarak değerlendirildi. Tüm cerrahi işlemler, y1llık 25 vaka ve üzeri hasta tecrübesine sahip 3 farklı cerrah tarafindan gerçekleştirildi. Çalışma, önceden yerel etik kurul onayı alınarak (Aydın Adnan Menderes Üniversitesi Tıp Fakültesi Girişimsel Olmayan Klinik Araştırmalar Etik Kurulu; Protokol No: 2020/191) ve Helsinki deklarasyonu ilkelerine uygun olarak yürütüldü. Verilerine ulaşılan 99 hasta (65 erkek, 34 kadın) çalışmaya dahil edildi. Tüm hastaların, komorbid hastalıkları, geçirilmiş taş cerrahisi öyküleri, yaş gibi demografik özelliklerinin yanı sıra taş tarafı, taş sayısı ve taş yükü, Hounsfield Unit (HU) değeri ve hidronefroz derecesi değerlendirildi. Hidronefroz düzeyi tanımlanırken, SFU (The Society for Fetal Urology) tarafindan önerilen derecelendirme sistemi kullanıldı (10). Derece 0 ve 1 hidronefroz hafif, derece 2 orta ve derece 3-4 ciddi dilatasyon olarak kabul edildi. Taş yükü, taşın en geniş çapı ile en uzun aksının çarpımı ile elde edilen iki boyutlu alan (mm2) olarak kabul edildi. Birden fazla taş varlığında toplam taş yükü, her bir taşın hesaplanan yüklerinin toplanması ile elde edildi. Operatif veriler içerisinde, perkütan giriş bölgesi, giriş sayısı, dilatasyon şekli, operasyon ve skopi süreleri, rest taş olup olmadığ1, raporlandı. Skopi süresi, renal ponksiyonun gerçekleştiği andan itibaren perkütan giriş yolunun oluşturulmasına kadar geçen sürede kullanılan toplam floroskopik görüntüleme zaman1, operasyon süresi ise ilk ponksiyondan başlayarak endoskopun ayrıldığı ana kadar geçen zaman olarak kabul edildi. Peroperatif ve postoperatif komplikasyonlar incelendi. Tüm hastalardan cerrahi öncesi rutin tam kan sayımı, kan kreatinin düzeyi ve idrar tetkikleri alındı. Postoperatif rutin tam kan sayımı yapıldı ve gereklilik halinde kan kreatinin düzeyi kontrol edildi. Postoperatif tam kan sayımı rutin olarak erken dönem olan ilk 6 saat içinde bakıldı. Ardından postoperatif 24. saat ve 48. saatte tekrar değerlendirildi. Gerekli olan hastalarda ek olarak 12. ve 36 . saatlerde ve kan tranfüzyonu yapılan hastalarda transfüzyon tamamlandiktan 2-4 saat sonra kontrol tam kan sayımları alındı. Preoperatif hemoglobin düzeyi normal sınırlarda (erkeklerde 13 gr/dl ve kadınlarda 12 $\mathrm{gr} / \mathrm{dl}$ üzerinde) olan hastalarda, $3 \mathrm{gr} / \mathrm{dl}$ üzerinde postoperatif hemoglobin düşüşü olan, aktif kanaması devam eden ya da düşüş miktarından bağımsız olarak kan basıncı düşüklüğü, taşikardi gibi semptomları mevcut olan hastalarda transfüzyon uyguland. Tüm hastaların kataterizasyon ve hospitalizasyon süreleri kaydedildi. Soliter böbrekli, supin perkütan 
nefrolitotomi operasyonu yapılan, atnalı böbrek anomalisi olan hastalar çalışmaya alınmadı.Cerrahi öncesi hastaların direk üriner sistem grafilerinin (DÜSG) yanı sira abdominopelvik bilgisayarlı tomografi (BT) ve/veya intravenöz piyelografi (IVP) görüntülemeleri yapıldı. Tüm hastaların cerrahi öncesi BT görüntülemeleri yapılarak taşa ait özellikler incelendi. Abdominopelvik BT görüntülemeler rutin olarak kontrastl1/kontrastsız çekimleri içeren BT urografi şeklinde gerçekleştirildi. Sadece kontrastsız BT tetkiki olan hastalarda, gereklilik halinde BT Urografi ya da IVP görüntülemeleri yapılarak üriner anatomi ve taş lokalizasyonları değerlendirilerek giriş yapılacak kaliksler belirlendi. Postoperatif tüm hastalarda DÜSG ve gereksinim halinde BT ile rezidüel taş açısından kontrol görüntülemeleri yapıldı. Fragmante taş boyutu $4 \mathrm{~mm}$ ve altında olan hastalarda taşsızlık (stone-free) sağlanmış kabul edildi.

\section{Cerrahi Teknik:}

Cerrahi yöntem, her iki merkezde de benzer şekilde uygulandı ve tüm hastalarda prone pozisyonda gerçekleştirildi. Öncelikle litotomi pozisyonunda işleme başlandı ve sistoskopi eşliğinde cerrahi taraf üretere 6 Fr üreter katateri yerleştirilerek 16 Fr foley sonda üzerine sabitlendi. Ardından prone pozisyona geçildi. Perkütan renal giriş, literatürde daha önce tanımlandığı gibi posterior aksiller hatta floroskopik görüntüleme eşliğinde uygun kaliksler seçilerek yapıldı (11). Cerrahın tercihine göre monoplanar ya da biplanar teknik kullanılarak renal giriş sağlandı ve toplayıcı sisteme 0,038 inch kılavuz tel yerleştirildi. Perkütan giriş hattına, 30 Fr'ye kadar dilatasyon uygulanarak $30 \mathrm{Fr}$ çalışma kılıfı yerleştirildi. Dilatasyon balon dilatatör veya amplatz seri dilatatörler kullanılarak yapıldı. Daha önce açık cerrahi uygulanan ve skar dokusu fazla olan hastalarda 14 Fr'ye kadar amplatz dilatatörler ile sonrasında balon dilatatörler ile dilatasyon uygulandı. Taş fragmantasyonu, pnömotik litotriptör ile yapılarak taş parçaları dışarı alındı. Perkütan giriş hattına operasyon tamamlandiktan sonra 16,18 veya 20 Fr re-entry nefrostomi kateteri veya foley sonda yerleştirildi. Foley kateter takılan hastalarda üreter kateteri hasta üzerinde bırakıldı. Özellikle kanaması olmayan ve intraoperatif rest taş izlenmeyen hastalarda ise üreter kateteri çekilerek, antegrad olarak 6 Fr D-J stent yerleştirildi. Bu hastalara nefrostomi tüpü yerleştirilmedi.

\section{Postoperatif Takip:}

Nefrostomi kateteri olarak foley sonda yerleştirilen hastaların, 24. saatte kanaması yoksa nefrostomileri alındı. Takibinde üriner kaçak yok ise 6-8 saat sonra üreter kateterleri çekildi. Hematürisi devam edenlerde üreter kateteri 24.saatte alınarak nefrostomili takip edildi. Bu hastalar ile re-entry nefrostomi kateteri takılan hastalarda ise genellikle 36-48. saatte değerlendirme yapılarak hematüri yoksa nefrostomi katateri alınması tercih edildi. Rest taşı kalan veya hematürisi olan hastalarda ise nefrostomi çekilmeden önce klempe edilerek 1slatma ya da ağrı olup olmadığ 1 değerlendirildi ve kateter sonuca göre çekildi. İntraoperatif ve postoperatif komplikasyonlar Clavien-Dindo sinıflama sistemine göre kaydedildi.
Hastalar, balon dilatasyon uygulananlar grup 1, amplatz seri dilatasyon yapılanlar grup 2 ve kombine dilatasyon yapılanlar grup 3 olarak sınıfland1. Farklı renal dilatasyon yöntemi uygulanan hastaların verileri ayrı ayrı analiz edildi.

\section{İstatistiksel Analiz:}

Araştırma verileri SPSS 21.0 istatistik programı kullanılarak değerlendirildi. Sürekli değişkenlerin normal dağılıma uygunluğu görsel (histogram ve olasılık grafikleri) ve analitik yöntemler (Kolmogorov-Smirnov/ Shapiro-Wilk testleri) kullanılarak araştırılmıştır. Araştırmanın tanımlayıcı istatistikleri için normal dağılıma uyan verilerde ortalama ve standart sapma, normal dağılıma uymayan verilerde ortanca, minimum ve maksimum kullanılarak gösterilmiştir. Araştırmada kategorik değişkenler arasında fark olup olmadığını göstermek için Ki Kare Testi kullanılmıştır. Bağımsız gruplarda sürekli değişkenlerin parametrik özellikleri taşıyanlarının karşıllaştırılmasında Student-t Testi veya One Way ANOVA, bağımsız gruplarda sürekli değişkenlerin parametrik özellikleri taşımayanlarının karşılaştırılmasında Mann Whitney U Testi veya Kruskal Wallis Varyans Analizi kullanılmıştır. İstatistiksel anlamlılık için p değerinin 0,05'ten küçük saptanması koşulu aranmıştır.

\section{Bulgular:}

Perkütan nefrolitotomi uygulanan toplam 101 renal ünitenin (99 hasta), 33'ü $(\% 32,7)$ grup 1, 49’u (\%48,5) grup 2 ve 19'u $(\% 18,8)$ grup 3 'te idi (Tablo I).

Tablo I: Gruplara göre demografik veriler ve taş özellikleri

\begin{tabular}{|c|c|c|c|c|}
\hline & $\begin{array}{c}\text { Grup 1 } \\
(n=33)\end{array}$ & $\begin{array}{l}\text { Grup2 } \\
(\mathrm{n}=49)\end{array}$ & $\begin{array}{c}\text { Grup 3 } \\
(n=19)\end{array}$ & $\mathbf{p}$ \\
\hline Yaș (Ortalama-yıl) (SS) & $46,70 \pm 15,77$ & $50,41 \pm 13,94$ & $44,68 \pm 16,83$ & 0,306 \\
\hline \multicolumn{5}{|l|}{ Cinsiyet $(\mathrm{n}-\%)$} \\
\hline Erkek & $22(\% 66,7)$ & $29(\% 59,2)$ & $15(\% 78,9)$ & \multirow{2}{*}{0,301} \\
\hline Kadın & $11(\% 33,3)$ & $20(\% 40,8)$ & $4(\% 21,1)$ & \\
\hline \multicolumn{5}{|l|}{ Cerrahi Taraf(n-\%) } \\
\hline Sol & $20(\% 60,6)$ & $29(\% 59,2)$ & $11(\% 57,9)$ & \multirow{2}{*}{0,981} \\
\hline Sağ & $13(\% 39,4)$ & $20(\% 40,8)$ & $8(\% 42,1)$ & \\
\hline $\begin{array}{l}\begin{array}{l}\text { Housfield Unit (Ort.) } \\
\text { (SS) }\end{array} \\
\end{array}$ & $\begin{array}{c}804,06 \\
\pm 276,16\end{array}$ & $\begin{array}{c}941,96 \\
\pm 322,96\end{array}$ & $\begin{array}{c}781,58 \\
\pm 253,05\end{array}$ & 0,049 \\
\hline $\begin{array}{l}\text { Taş Yükü (Ort.-mm2) } \\
\text { (SS) }\end{array}$ & $\begin{array}{c}735,85 \\
\pm 471,06\end{array}$ & $\begin{array}{l}1603,53 \\
\pm 2348,9\end{array}$ & $\begin{array}{l}746,42 \\
\pm 552,8\end{array}$ & 0,284 \\
\hline \multicolumn{5}{|l|}{$\begin{array}{l}\text { Hidronefroz Derecesi } \\
(\%)\end{array}$} \\
\hline Hafif & 33,3 & 30,6 & 31,6 & \multirow{3}{*}{0,838} \\
\hline Orta & 45,5 & 36,7 & 36,8 & \\
\hline İleri & 21,2 & 32,7 & 31,6 & \\
\hline
\end{tabular}

(n): Hasta sayıs1, (Ort.): Ortalama, $\mathrm{p}<0,05$ istatistiksel olarak anlamlı kabul edilmiştir.

Tüm hastaların ortalama yaşı $48,12 \pm 15,14$ yıl olarak saptand 1 ve gruplar arasında yaş dağılımı açısından anlamlı fark izlenmedi ( $\mathrm{p}=0,306)$. Renal taş yükü bakımından gruplar arasında anlamlı fark izlenmedi ( $p=0,284)$. Grup 2'de HU değeri diğer gruplara göre daha yüksekti. Ondokuz hastada geçirilmiş açık taş cerrahisi öyküsü mevcuttu. Ortalama operasyon süresi $73,12 \pm 39,27 \mathrm{dk}$ olarak saptand 1 ve gruplar arasında anlamlı fark izlenmedi $(\mathrm{p}=0,185)$. Taşsızlık oranları açısından gruplar birbiri ile benzer saptandi. Ortalama nefrostomi çekilme süreleri gruplar arasında sırasıyla grup 1: 1,58 $\pm 0,61$ gün, grup 
2: 3,41 $\pm 2,23$ gün ve grup 3: 2,32 $\pm 1,73$ gün olarak saptand 1 $(\mathrm{p}<0,001)$ (Tablo II). Benzer şekilde hastanede kalış süreleri de sirasiyla 2,36 $\pm 1,27$ gün, 4,53 $\pm 2,69$ gün ve 3,79 $\pm 2,53$ gün idi $(p<0,001)$. Postoperatif hemoglobin düşüşü açısından bakıldığında, en fazla grup 3'te azalma olduğu görüldü ve bu istatistiksek olarak anlamlı izlendi $(p<0,05)$. Yine gruplar kendi aralarında incelendiği zaman da grup 1 ve 2'ye karşı grup 3'te daha fazla hemoglobin düşüşü vard1 ve bu istatistiksel olarak anlamliyd 1 (Grup 1/Grup 3 p=0,026 ve Grup 2/Grup $3 \mathrm{p}=0,004)$. Grup 1 ve grup 2 arasında ise grup 1'de önemli derecedeki hemoglobin düşüşü daha fazla ise de istatistiksel anlamlılık yoktu ( $\mathrm{p}=0,373)$. Benzer şekilde hematokrit düşüşü bakımından da grup 3 istatistiksel olarak en fazla azalma görülen gruptu $(\mathrm{p}<0,05)$. Postoperatif hematokrit düşüşü Grup 3 'te grup $1(p=0,112)$ ve grup 2'ye $(p=0,001)$ göre daha fazla idi. Grup 1 ve 3 'te birer ve grup 2'de ise iki hastada birden fazla giriş yapılmıştı. Bunlar orta pol seviyesindeki girişlerdi. Hasta sayısı az olması nedeni ile, giriş sayısı ve seviyesinin kanama üzerine etkisi değerlendirilemedi. Komplikasyon oranları bakımından en az komplikasyon balon dilatasyon grubunda izlenmiş olmakla birlikte istatistiksel anlamlı farklılık saptanmadı (Tablo II).

Tablo II: Gruplar arası operatif verilerin karşılaştırılması

\begin{tabular}{|l|c|c|c|c|}
\hline & $\begin{array}{c}\text { Grup 1 } \\
(\mathbf{n = 3 3 )}\end{array}$ & $\begin{array}{c}\text { Grup2 } \\
(\mathbf{n = 4 9 )}\end{array}$ & $\begin{array}{c}\text { Grup 3 } \\
(\mathbf{n = 1 9 )}\end{array}$ & $\mathbf{p}$ \\
\hline Op. Süresi (Ort.-Dk.) & 64,03 & 75,00 & 84,05 & 0,185 \\
\hline Taşsızlık Oranı (\%) & 54,5 & 38,8 & 52,6 & 0,313 \\
\hline $\begin{array}{l}\text { Nefrostomi Süresi (Ort.- } \\
\text { gün) }\end{array}$ & 1,58 & 3,41 & 2,32 & $\mathbf{0 , 0 0 0}$ \\
\hline $\begin{array}{l}\text { Hastanede Kalıs Süresi } \\
\text { (Ort.-gün) }\end{array}$ & 2,36 & 4,53 & 3,79 & $\mathbf{0 , 0 0 0}$ \\
\hline$\Delta$ Hb (Ort.-mg/dl) & 1,39 & 1,23 & 2,43 & $\mathbf{0 , 0 1 6}$ \\
\hline$\Delta$ Htc (Ort.-mg/dl) & 3,54 & 3,31 & 6,57 & $\mathbf{0 , 0 0 3}$ \\
\hline Transfüzyon (\%) & 3 & 2,1 & 36,8 & $\mathbf{0 , 0 0 0}$ \\
\hline Komplikasyon (\%) & 15,2 & 37,5 & 47,4 & 0,053 \\
\hline
\end{tabular}

(n): Hasta sayısı, (Ort.): Ortalama, $\Delta \mathrm{Hb}$ : Hemoglobin düşüşü (Preoperatif $\mathrm{Hb}$ - Postoperatif Hemoglobin), $\Delta$ Htc: Hematokrit düşüşü (Preoperatif Hematokrit - Postoperatif Hematokrit), $\mathrm{p}<0,05$ istatistiksel olarak anlamlı kabul edilmiştir.

Yine tranfüzyon oranları grup 1 ve 2'de benzer iken grup 3'te anlamlı düzeyde yüksekti $(\mathrm{p}<0,001)$.

\section{Tartışma:}

Perkütan nefrolitotomi, ilk tanımlandığı zamandan itibaren önemi ve kullanımı giderek artan endoürolojik girişimlerden biri olmuştur (5). Günümüzde staghorn ve büyük hacimli böbrek taşları, kaliks divertikül taşları, alt pol yerleşimli renal taşlar, sistin taşları, üriner sistem anomalileri ile ilişkili taşlar ve diğer tedavi yöntemlerinin başarısız olduğu durumlarda PNL endikedir $(6,12)$. Literatürde yapılan çalışmalar, PNL'nin güvenilir ve etkin bir cerrahi yöntem olduğunu göstermiştir $(6,13,14) . \% 80$ 'in üzerinde taşsızlık oranları ve düşük morbiditeye sahip olması en önemli avantajlarıdır (14). Tanımlandığı ilk zamanlardan günümüze kadar artan cerrahi tecrübe ve teknik ilerlemeler, PNL'nin komplikasyon oranlarında azalma sağlanmıştır. Perkütan nefrolitotomiyi daha da etkili ve güvenli hale getirebilmek için hem cerrahi teknik, hem de ekipmanlar üzerinde araştırmalar devam etmektedir. Klasik prone pozisyondan supin pozisyona kadar değişen farklı cerrahi pozisyonlar, farklı trakt dilatasyon metotları, farklı çaplarda ve özellikte nefroskoplar ile drenajı sağlayacak farklı ekipmanlar bu amaçla yapılan çalışmalar ile ortaya çıkmıştır (14).

Perkütan nefrolitotomide komplikasyonlar, böbreğe giriş esnasında, dilatasyon aşamasında ve taş ektirpasyonu sırasında oluşabilmektedir. Genel komplikasyon oranları literatürde \%29 ile \%83 arasında değişmektedir (14). Ancak bunların büyük kısmı klinik önemi olmayan minör komplikasyonlardır (15). Perkütan giriş sırasında gözlenebilen komplikasyonlar, renal hemoraji, perkütan girişte başarısızlık, hidrotoraks ve pnömotoraks gibi torasik komplikasyonlar ile barsak ve diğer abdominal organ yaralanmalarıdır (12). Renal ponksiyon sonrasındaki dilatasyon esnasında ise, renal parankimal ve toplayıcı sistem yaralanmaları $(\% 0,2-5,2)$, kanama $(\% 7-11,5)$ ve dilatasyonda başarısızlık $(\% 0,8-2,4)$ gibi komplikasyonlar önemli oranlarda karşımıza çıkmaktadır $(16,17)$. Bu nedenle uygulaması basit, etkili ve güvenilir bir dilatasyon yöntemi geliştirilmeye çalışılmaktadır. Perkütan giriş yolu oluşturulurken balon dilatatörler, amplatz seri dilatatörler ve metal teloskopik dilatatörler kullanılabilmektedir.

Balon dilatatörler, en modern yöntem olmakla birlikte daha yüksek maliyet problemini de getirmektedir (18). Alternatif olarak amplatz ve alken tip dilatatörlerdeki ardışık uygulamaları ortadan kaldırmak üzere one-shot dilatasyon yöntemi tanımlanmış, güvenli ve etkin bir yöntem olarak floroskopi süresi ve kanama miktarını azalttığı, balon dilatatörlere göre maliyet avantajı sağladığı gösterilmiştir $(19,20)$.

Balon dilatatörlerin kolay kullanım ve hılı uygulama avantajları mevcuttur. Uzunlamasına eksende tekrarlayan girişlere gereksinim olmadan tek seferde radyal düzlemde belirlenen çapa kadar genişleme sağlayabilmesi, parankimal hasarlanma ve kanama riskini azaltmaktadır. Aynı zamanda tek seferde hızlı giriş hattı meydana getirmesi, tekrarlayan uygulamalarda gözlenebilen kılavuz tel kırılması ve giriş hattının kaybedilmesi gibi riskleri de düşürmektedir. (21). Bu hızlı uygulama, daha kısa floroskopi süresi ve operasyon süresi sağlamaktadır (22). Çalışmamızda balon dilatasyon yöntemi kullanılan hastaların floroskopi süreleri analiz edilmediğinden karşılaştırma yapılamadı. Grup 3 hastalarda, grup 2'ye göre skopi süresi daha uzun olmakla birlikte istatistiksel olarak anlamlı değildi. Her ne kadar teorik olarak balon dilatasyon yöntemi giriş süresini kısaltsa da, operasyon süresi açısından anlamlı fark yaratmadığını gösteren veriler de mevcuttur (23). Bunun dışında CROES çalışması, tecrübe arttıkça dilatasyon sürelerinin kısaldığını ortaya koymuştur. Orta düzeyde vaka yoğunluğu olan merkezlerde balon ve amplatz/alken dilatatörlerin kullanımı ile anlamlı fark yokken özellikle vaka sayısı yüksek merkezlerde ardışık dilatasyon yöntemlerinin balon dilatasyona göre daha hızlı olduğu gösterilmiştir (9). Bizim verilerimiz de bunu destekler niteliktedir. Çalışmamızda, gruplar arasında taş yükü bakımından her ne kadar grup 2 daha yüksek taş yüküne sahip ise de istatistiksel olarak gruplar arasında anlamlı bir fark izlenmedi. 
$\mathrm{Bu}$ veriler eşliğinde değerlendirildiği zaman, operasyon süreleri bakımından da gruplar arasında istatistiksel anlamlı fark yoktu $(\mathrm{p}=0,185)$. Ancak çalışmamızda grup 1 en kısa, grup 3 ise en uzun ameliyat süresine sahipti. Bu durumun perirenal fibrozis nedeni ile dilatasyonun daha zor olmasına bağlı olabileceği düşünüldü (24).

Literatürde PNL için genel komplikasyon oranları geniş bir aralıkta verilmekle birlikte çok merkezli bir seride bu oran \%21,5 olarak rapor edilmiştir (13). Çalışmamızda, erken dönem komplikasyon oranı \%31,68 (32 hasta) olarak saptanmıştır. Bunların büyük çoğunluğu $(\% 68,75 ; n=22)$ postoperatif ağrı, geçici ateş yüksekliği, kanama nedeni ile transfüzyon gereksinimi ya da antibiyotik tedavisi gerektiren yüksek ateş gibi Clavien 1 ve 2 komplikasyonlard. On $(\% 31,25)$ hastamızda ise Clavien 3a/3b komplikasyonlar gözlendi. Bunlarda da en sık neden, uzamış idrar kaçağı nedeni ile anestezi altında double-J stent takılması gerekliliği idi. Clavien 4 ve 5 komplikasyon ise izlenmedi. Geçirilmiş cerrahilerin, daha uzun operasyon süresi, daha fazla kanama ve daha düşük taşsızlık oranı gibi sonuçlara etki edebileceği ancak komplikasyon oranları açısından fark yaratmadığ 1 gösterilmiştir. (25). Bulgularımız, kombine yöntemin kullanıldığı ve geçiriliş cerrahi öyküsü olan grup 3 hastalarda daha fazla clavien 1-3 komplikasyon göstermekteydi. Ancak literatür ile benzer şekilde gruplar arasında komplikasyon dağılımı bakımından fark izlenmemekteydi $(24,26)$.

Kanama, en sık görülen komplikasyondur. \%11-17,5 arasında değişen oranlarda karşımıza çıkmakla birlikte transfüzyon gereksinimi, \%1-2,5 civarındadır. Teorik olarak, balon

dilatasyon sırasında küçük damarlara uygulanan

kompresyonun, kanamayı azaltan bir faktör olabileceği düşünülmektedir (21). Literatürde balon dilatatörlerin, amplatz ve metal teloskopik dilatatörlere göre daha az postoperatif hemoglobin düşüşü sağladığını gösteren yayınlar mevcuttur (18). CROES çalışmasında ise aksine balon dilatasyonun seri dilatasyona göre daha fazla kanama ve transfüzyon ile ilişkili olduğu bulunmuştur (9). Gönen ve arkadaşları, amplatz ve balon dilatasyon yöntemleri arasında, kanama ve transfüzyon oranları açısından anlamlı fark olmadığını göstermişler ve her iki yöntemin dokuyu yırtmak yerine genişleterek benzer parankimal hasara sebep olduğunu ifade etmişlerdir (23). Çalışmamızda, cerrahiye bağlı kan kaybının göstergesi olan parametrelerden postoperatif hemoglobin ve hematokrit düşüşü, en fazla grup 3 hastalarda izlendi. Grup 1 hastalarda kanama, grup 2'ye göre daha fazla olmakla birlikte istatistiksel olarak anlamlı değildi. Transfüzyon gereksinimi bu gruplar arasında benzerdi ve en yüksek transfüzyon gereksinimi kombine yöntemin kullanıldığ grup 3 'teydi. $\mathrm{Bu}$ verilerde literatüre benzer şekilde amplatz ve balon dilatasyon yöntemlerinin kanama ve tranfüzyon ihtiyacı bakımından birbirine fark yaratmadığını desteklemektedir. Geçirilmiş renal cerrahi öyküsünün PNL sonrası daha fazla kanama ve postoperatif hemoglobin düşüşü ile ilişkisi bilinmektedir (25). Cerrahiye bağlı perinefritik skar dokusunun cerrahi esnasinda daha fazla renal laserasyon ve kanamaya neden olabileceği (25) ve aynı zamanda parankimal adezyonlara bağlı neovaskülarizasyonun da kanama riskini arttırabileceği gösterilmiştir (27). Bu bakımdan özellikle grup 3 hastalarda daha fazla postoperatif hemoglobin düşüşü olması, hastaların geçirilmiş renal cerrahi öykülerine bağlı olabilir.

Balon dilatatörlerin dezavantajlarından biri de geçirilmiş cerrahi ya da enflamasyon durumlarında ortaya çıkan perinefritik skar dokusunda etkinliğinin azalmasıdır. Aynı zamanda staghorn taşlar, kaliks divertikül taşları ya da yetersiz dilatasyonu olan toplayıcı sistem varlığında kılavuz tel kayması ve başarısız dilatasyon risklerinin fazla olduğu gösterilmiştir (28). Aksine amplatz fasiyal dilatatörlerin, perirenal fibrozis ve staghorn taşlarda, balon dilatatörlere göre daha etkin olduğu da bildirilmiştir (29). Çalışmamızda, 2 hasta başarısız giriş nedeni ile sonlandırıldı. Her iki hastada da daha önceki açık cerrahi uygulamalara bağlı ciddi fibrozis mevcuttu. $\mathrm{Bu}$ hastalar, kombine dilatasyon yapılan grup 3 hastalardand. Bir hastada, balon dilatasyon esnasinda kilavuz tel dislokasyonuna bağlı olarak toplayıcı sisteme ulaşılamadı. Diğer hasta, transfüzyon gerektiren hastalardan biriydi ve burada balon dilatasyon, renal skarı genişletmekte yetersiz kaldı. Bunun üzerine amplatz dilatasyon ile işleme devam edildi. Toplayıcı sisteme ulaşılmış olsa da hemoraji nedeni ile işlem sonlandırıldı. Geç dönem kontrollerde de anjioembolizasyon gerektirecek herhangi hemorajik komplikasyon gelişmedi.

Perkütan nefrolitotominin kısa hastanede kalıs avantajı onun tercih edilen bir tedavi yöntemi olarak kullanımını arttırmıştır (30). Bununla birlikte kullanılan dilatasyon yöntemlerinin hastanede kalış süresi üzerine etkileri de çeşitli çalışmalarda incelenmiştir. Balon dilatasyonun, amplatz seri dilatasyona göre daha kısa hastanede kalış avantajı sağladığı gösterilmekle birlikte anlamlı fark ortaya konulamamıştır (31).

Verilemiz, grup 1 hastalarda en kısa hastanede kalış süresi olduğunu göstermektedir. Grup 2 ve grup 3 hastalarda ise hastanede kalış süreleri benzerdi. Buradaki farkın yerleştirilen nefrostomi kateterinin tipine bağlı olabileceği düşünüldü. Balon dilatasyon yapılan hastalarda genellikle üreter kateteri hasta üzerinde bırakılarak uygun çapta bir foley sonda nefrostomi tüpü olarak yerleştirilmekteydi. Amplatz ve kombine dilatasyon yapılan hastalarda ise çoğunlukla reentry nefrostomi tercih edildi. Üreter kataterinin hasta üzerinde kalması uygun hastalarda nefrokutanöz fistül riski olmadan erken nefrostomi alınmasını teşvik eden bir faktördü. Reentry nefrostomi takılan hastalarda ise üreter katateri alındığından daha kontrollü yaklaşıldı. Bu fark hastanede kalış süresi doğrudan etkilemiş olabilir.

Rijit dilatatörler etkinlik, maliyet ve komplikasyonlar açısından oldukça efektif bir yöntem olmakla birlikte yaygın olarak birçok merkez tarafindan da tercih edilmektedir. Balon dilatatörler en modern yöntem olarak bazı avantajlara sahip olsa da maliyet dezavantajı nedeniyle kullanımı kısitlı kalmaktadır. Ancak tecrübeye bağlı olarak yöntemlerin birbirine göre anlamlı bir üstünlükleri de bulunmamaktadır. Çalışmamızın en önemli kısıtlayıcı yönü retrospektif olmasıdır. Yine hasta sayılarımızın az olması, vücut/kitle indeksinin değerlendirilememiş olması, floroskopi sürelerinin eksik olması, maliyet analizi yapılamamış olması ve farklı merkezlerin çalışmayı yürütmeleri çalışmanın sınırlılık 
Kol A. ve ark.

oluşturan taraflarıdır. Bu nedenle daha geniş hasta serileri içeren, prospektif ve randomize kontrollü çalışmalar ile bulguların desteklenmesi önerilmektedir.

\section{Sonuç:}

Perkütan nefrolitotomide amplatz seri dilatatörler, hızlı uygulama avantajına sahip balon dilatatörler ile benzer taşsızlık ve komplikasyon oranları sağlamaktadır. Ek olarak geçirilmiş cerrahi öyküsü olan hastalarda, yöntemlerin kombine uygulamaları fayda sağlayabilir.

\section{Etik Komite Onayı:}

Çalışma, Aydın Adnan Menderes Üniversitesi Tıp Fakültesi Girişimsel Olmayan Klinik Araştırmalar Etik Kurulu'nun 15.10.2020 tarihli toplantısında alınan kararlar doğrultusunda 2020/191 protokol numarası ve 13. No'lu kararı ile onaylanmiştır.

Yazar Katkisı:

Çalışma Fikri

Denetleme

: AK, EA, TI

Veri Toplama ve İşleme

: AK, EA, TI

: AK, EA, TI

: AK, EA, TI

Literatür Taranmasi $\quad$ : AK, EA, TI

Makale Yazımı : AK, EA, TI

Eleştirisel İnceleme : : AK, EA, TI

Kaynaklar ve Fon Sağlama : AK, EA

Malzemeler : AK, EA, TI

\section{Çıkar Çatışması:}

Yazarlar arasında herhangi çıkar çatışması beyân edilmemektedir.

\section{Finansal Destek:}

Yazarlar bu çalışma için herhangi bir finansal destek almadıklarını beyân etmişlerdir.

\section{Kaynaklar/References:}

1- Alelign T, Petros B. Kidney Stone Disease: An Update on Current Concepts. Adv Urol. 2018; Article ID 3068365.

2- Romero V, MD, Akpinar H, MD, Assimos DG. Kidney Stones: A Global Picture of Prevalence, Incidence, and Associated Risk Factors. Rev Urol. 2010; 12(2-3): e86-e96.

3- Moe O. W. Kidney stones: pathophysiology and medical management. The Lancet. 2006;367(9507):333-344.

4- Knoll T. Epidemiology, Pathogenesis, and Pathophysiol ogy of Urolithiasis. Eur. Urol. Suppl. 2010; 9(12): 802-806.

5- Fernström I, Johansson B. Percutaneous pyelolithotomy. A new extraction technique. Scand J Urol Nephrol. 1976; 10(3):257-259.

6- Türk C, Neisius A, Petrik A, Seitz C, Skolarikos A, Thomas K. EAU Guidelines on Urolithiasis, 2018. https://uroweb.org/guideline/urolithiasis/

7- Michel MS, Trojan L, Rassweilwe JS. Complications in percutaneous nephrolithotomy. Eur Urol. 2007; 51:899-906.

8- Ko R, Soucy F, Denstedt JD, Razvi H. Percutaneous nephrolithotomy made easier: a practical guide, tips and tricks. BJU Int. 2008;101(5):535-539.

9- Yamaguchi A, Skolarikos A, Buchholz NP, Chomon GB, Grasso P, Saba P, Nakada S, De La Rosette J, Clinical Research Office Of The Endourological Society Percuta neous Nephrolithotomy Study Group. Operating times and bleeding complications in percutaneous nephrolitho tomy: a comparison of tract dilation methods in 5,537 patients in the Clinical Research Office of the Endouro logical Society Percutaneous Nephrolithotomy Global Study. J Endourol. 2011; 25:933-9.

10- Fernbach SK, Maizels M, Conway JJ: Ultrasound grading of hydronephrosis: Introduction to the system used by the Society for Fetal Urology. Pediatr Radiol. 1993; 23: 478-480.

11- Lee WJ, Smith AD, Cubelli V, Vemace FM. Percutaneous nephrolithotomy: analysis of 500 consecutive cases. Urol Radiol. 1986; 8:61-66.

12- Watterson JD, Soon S, Jana K. Access Related Complica tions During Percutaneous Nephrolithotomy: Urology Versus Radiology at a Single Academic Institution. J Urol. 2006; 176:142-145.

13- De la Rosette J, Assimos D, Desai M, Gutierrez J, Linge man J, Scarpa R, Tefekli A, CROES PNL Study Group. The clinical research office of the endourological society percutaneous nephrolithotomy global study: indications, complications, and outcomes in 5803 patients. J Endou rol. 2011; 25:11-17.

14- Miller NL, Lingeman JE. Management of kidney stones. BMJ 2007;334:468-472.

15- Skolarikos A, De La Rosette J. Prevention and treatment of complications following percutaneous nephrolithoto my. Curr Opin Urol. 2008; 18:229-234. 
16- Kallidonis P, Panagopoulos V, Kyriazis I, Liatsikos E. Complications of percutaneous nephrolithotomy: Classi fication, management and prevention. Curr Opin Urol. 2016; 26:88-94.

17- Srivastava A, Singh S, Dhayal IR, Rai P. A prospective randomized study comparing the four tract dilation meth ods of percutaneous nephrolithotomy. World J Urol. 2017; 35: 803-807.

18- Wu Y, Xun Y, Lu Y, Hu H, Qin B, Wang S. Effectiveness and safety of four tract dilation methods of percutaneous nephrolithotomy: A meta-analysis. Exp Ther Med. 2020;19: 2661-2671.

19- Frattini A, Barbieri A, Salsi P, Sebastio N, Ferretti S, Bergamaschi E, Cortellini P. One shot: A novel method to dilate the nephrostomy access for percutaneous lithotrip sy. J Endourol. 2001; 15: 919-923.

20- Ucar M, Kisa E, Celik F, Yucel C, Suelozgen T, Ilbey YO, Kilic N. Can single-step dilatation technique in pediatric percutaneous nephrolithotomy be an effectice alternative to stepwise dilatation? J Surg Med. 2019; 3(8):583-587.

21- Joel AB, Rubenstein JN, Hsieh MH, Chi T, Meng MV, Stoller ML. Failed Percutaneous Balloon Dilation For Renal Access: Incidence And Risk Factors. Urology. 2005; 66: 29-32.

22- Wezel F, Mamoulakis C, Rioja J, Michel MS, De la Rosette J, Alken P. Two Contemporary Series of Percuta neous Tract Dilation for Percutaneous Nephrolithotomy. J Endourol. 2009; 23(10): 1655-1661.

23- Gonen M, Istanbulluoglu OM, Cicek T, Ozturk B, Ozkardes H. Balloon Dilatation versus Amplatz Dilata tion for Nephrostomy Tract Dilatation. J Endourol. 2008; 22(5): 901-904.

24- Reddy SVK, Shaik AB. Outcome and complications of percutaneous nephrolithotomy as primary versus second ary procedure for renal calculi. Int Braz J Urol. 2016; 42(2):262-269.
25- Hu H, Lu Y, Cui L, Zhang J, Zhao Z, Qin B, Wang Y, Wang Q, Wang S. Impact of previous open renal surgery on the outcomes of subsequent percutaneous nephroli thotomy: a meta-analysis. BMJ Open 2016; 6:e010627.

26- Margel D, Lifshitz DA, Kugel V, Dorfmann D, Lask D, Livne PM. Percutaneous nephrolithotomy in patients who previously underwent open nephrolithotomy. J Endourol. 2005; 19:1161-1164.

27- Ozgor F, Kucuktopcu O, Sarılar O, Toptas M, Simsek A, Gurbuz ZG, Akbulut MF, Muslumanoglu AY, Binbay M. Does previous open renal surgery or percutaneous neph rolithotomy affect the outcomes and complications of percutaneous nephrolithotomy. Urolithiasis. 2015; 43(6):541-547.

28- El-Shazly M, Salem S, Allam A, Hathout B. Balloon dilator versus telescopic metal dilators for tract dilatation during percutaneous nephrolithotomy for staghorn stones and calyceal Stones. Arab J Urol.2015; 13:80-83.

29- Kumar V, Keeley FX. Percutaneous Nephrolithotomy: Why Do We Use Rigid Dilators? J Endourol. 2008; 22 (9): 1877-1879.

30- Alyami F, Norman RW. Is an overnight stay after percu taneous nephrolithotomy safe? Arab J Urol. 2012; 10(4): 367-371.

31- Pakmanesh H, Daneshpajooh A, Mirzaei M, Shahes maeili A, Hashemian M, Alinejad M, Ketabchi AA, Tavoosian A, Ebadzadeh MR. Amplatz versus Balloon for Tract Dilation in Ultrasonographically Guided Percu taneous 